\title{
que se aprende com as princesas da Disney?
}

Resumo: Neste artigo, problematizam-se os modos como imagens femininas são produzidas pelas grandes corporações de brinquedos, focalizando as princesas da Disney. Discute-se o modo como essas imagens estereotipadas produzem efeitos nas subjetividades infantis. A criação dessas personagens está ligada a uma representação do ideal de feminilidade da cultura contemporânea: brancas, ocidentais, heterossexuais, ostentando os ideais da nobreza e da burguesia. Por estarem presentes na cultura lúdica infantil, é preciso que se reflita sobre a pedagogia cultural dessas personagens, que apresentam modos de subjetivação das crianças, ensinando-as sobre o "mundo encantado Disney".

Palavras-chave: Princesas, Disney, Pedagogias Culturais, Subjetivação.

\section{What you learn with Disney princesses?}

Abstract: This paper problematize the ways female images are produced by large corporations toys, focusing the Disney princesses. It discusses how these stereotypical images produce effects in children's subjectivities. The creation of these characters is linked to a representation of the ideal of womanhood in contemporary culture: white, western, heterosexual, sporting ideals of the nobility and the bourgeoisie. Being present in infant play culture, it is necessary to reflect on the cultural pedagogy of these characters, who present modes of subjectivity children, teaching them about the "Disney enchanted world". Keywords: Princesses, Disney, Cultural Pedagogy, Subjectivity. 
odeadas por castelos suntuosos, bruxas, madrastas más, vilões, fadas madrinhas, príncipes encantados, anões e florestas perigosas, as princesas da Disney apresentam um ideal de beleza, comportamento e amor romântico próprios da nobreza aristocrática, que ainda prevalecem no imaginário popular no século XXI. Baseadas nos contos de Perrault (1628 - 1703), dos irmãos Jacob (1785 - 1863) e Wilhelm Grimm (1786 - 1859) e de Andersen (1805 - 1875), suas histórias se tornaram filmes de animação em versões mais “açucaradas" pelos estúdios Disney. Com os lançamentos dos filmes, as princesas foram transformadas em bonecas e estampam inúmeros produtos voltados para as crianças, desde jogos e brinquedos, roupas e materiais escolares.

Os modos como as imagens femininas são produzidas pelas grandes corporações de brinquedos, focalizando as bonecas princesas da Disney, são problematizados neste artigo. Discutese o modo como essas imagens estereotipadas produzem efeitos nas subjetividades infantis, tendo em vista que a cultura é uma construção social e psíquica dos sujeitos, a educação não está restrita às escolas, às universidades, à igreja ou à família, mas a todas as formas de propagação da cultura (GIROUX, 2004).

A escolha pelas princesas como objeto de análise deve-se ao fato de serem personagens elaboradas para filmes de animação de uma grande corporação. A criação dessas personagens está ligada a uma representação do ideal de feminilidade da cultura contemporânea: brancas, ocidentais, heterossexuais, ostentando os ideais da nobreza e da burguesia. Por estarem presentes na cultura lúdica infantil, é preciso que se problematize a pedagogia cultural das princesas, que apresentam modos de subjetivação das crianças, ensinando-as sobre o "mundo encantado Disney".

\section{E Foram Felizes para Sempre}

Optou-se pelo final feliz dos contos de fadas retratados pelos filmes das princesas da Disney por ser muito mais do que um chavão deste "poderoso reino" norte-americano. Essa felicidade é vendida por uma das corporações de entretenimento mais importantes do mundo. A Walt Disney é um "império" que poderia ser dispensado de apresentações, pois seus produtos estão presentes no 
cotidiano das crianças e muitos de nós cresceram alimentados por seu "mundo de sonhos". As músicas, as cores, as danças, os personagens e as narrativas vendem a felicidade, o sonho, o gozo e a magia que esses filmes remetem (GOMES, 2000). Todos os produtos criados a partir dos filmes e do próprio parque temático prometem o final feliz que alimenta as multidões ávidas por vivenciar a aura mágica dos contos de fadas.

Walter Elias Disney (1901 - 1966) foi o idealizador desta “terra encantada", onde as aventuras dos filmes e os personagens são vividos em um parque de diversões, que se tornou o símbolo de uma grande corporação que vende entretenimento para praticamente todo o mundo. O slogan "eu acredito em fadas", alusivo ao filme Peter Pan, promete a realização de sonhos na possibilidade de encontrar os personagens da Disney, inclusive a Cinderela, sua carruagem e seu castelo. Isto é, a Disney faz parecer que existem aqueles personagens de contos de fadas e desenhos animados. O sonho realizado prometido é o sonho de consumo acompanhado da promessa de gozo e satisfação "mágica".

Os fogos de artifício, as fantasias bem elaboradas, as paradas luminosas e os shows de luzes fazem parte da construção do imaginário Disney, caracterizando sua marca. Ao se falar em marca, ela não é vista apenas como registro de patente ou como a impressão de um produto elaborado com qualidade técnica por determinada corporação, mas como uma "entidade" disseminadora de crenças e valores através dos seus produtos e serviços. O final feliz é vendido através de imagens e narrativas que remetem ao que é bom, agradável, positivo e luminoso e, também, à vitória e ao herói.

Por outro lado o mal é retratado pela Disney como escuridão, sombra, visceralidade, sujeira, caos e velhice, tal qual os conceitos próprios da idade média, que ainda estão presentes na cultura de massa no século XXI. Deleuze (1998), em sua obra Foucault, evidencia o medo do "mal" como o medo de ir além do saber-poder; é o medo de romper com os discursos dominantes e a necessidade de inventar outros modos de existência. Nessa lógica indagamos se há possibilidades para agir e imaginar modos de conduzir a vida em que não se esteja a espera do príncipe encantado em seu cavalo branco, com direito a castelos e fadas madrinhas?

Nesse processo de disseminar ainda mais seu "mundo encantado", a franquia das princesas da Disney tem produzido um grande volume de produtos para as crianças em âmbito global. A marca Disney Princess foi criada no ano 2000 quando Andy Mooney, ex-produtor da marca Nike de produtos esportivos, recém-contratado pela Disney, foi assistir a um espetáculo de patinação no gelo, Disney On Ice, e se deparou com uma multidão de meninas fantasiadas com roupas e acessórios das princesas. Essas fantasias não eram oficiais da marca, pois ainda não se fabricavam produtos próprios das princesas. Ao perceber o fascínio dessas meninas pelas princesas, o produtor teve a ideia de fundar a franquia, que tem sido "a mais bem-sucedida franquia de brinquedos da Disney" (DISNEY 
CONSUMES PRODUCTS, 2007) e reúne dez heroínas dos filmes de animação: Branca de Neve do filme Branca de Neve e os Sete Anões, Jasmine de Aladim, Bela de a Bela e a Fera, Pocahontas, Mulan, Cinderela e Ariel de A Pequena Sereia, Aurora de A Bela Adormecida, Tiana de a Princesa e o Sapo, e Rapunzel de Enrolados.

A linha de produtos licenciados da marca com as personagens do filme, voltada para jovens meninas, inclui filmes de animação, DVDs, brinquedos, CDs de música, livros, sites, jogos, roupas, material escolar, maquiagem e produtos de higiene (WOHLWEND, 2008). Tais artefatos apresentam às meninas um modelo de identidade feminina, ensinando modos de se vestir e de se comportar, indicando esse modelo como o esperado para o gênero feminino, convidando-as a se identificarem com as personagens.

Tendo em vista que as identidades infantis e suas representações são produzidas pelos discursos que se enunciam sobre ela, as representações sociais da infância são moldadas na e pela linguagem. A "virada linguística" concebe a linguagem como constituidora, em outras palavras, a linguagem forma sistematicamente os objetos sobre os quais narram. A cada época histórica forjamse modelos hegemônicos, e certas narrativas são tidas como verdadeiras. As narrativas agora passam a ser vistas como formadoras do sujeito e, de acordo com Larrosa (1996), elas produzem as identidades, partindo-se da ideia de que somos o que contamos e o que nos contam, sob a influência dos lugares, tempo e vozes que narram, fazendo com que a narrativa se torne responsável pela formulação dos processos identitários. Com a virada linguística, a verdade única deixa de existir, sendo substituída por verdades constituídas. Estas, a partir de então, são consideradas crenças e têm como alvo de análise o processo pelo qual algo se torna verdade (SILVA, 2007). Foucault (1993) explica que a linguagem e, consequentemente, os discursos não funcionam imunes aos controles sociais porque são atravessados pelas relações de poder.

\footnotetext{
Cada sociedade tem seu regime de verdade, sua política geral, de verdade: isto é, os tipos de discurso que aceita e faz funcionar como verdadeiros; os mecanismos e instâncias que permitem distinguir entre sentenças verdadeiras e falsas, os meios pelos quais cada um deles é sancionado (FOUCAULT, 1993, p. 12).
}

$\mathrm{Na}$ crescente profusão de imagens nas quais as crianças estão imersas, determinados modos de pensar, agir e ser são ensinados e reconhecidos como legítimos. A educação imagética está cada vez mais presente na vida cotidiana das crianças, tornando-se um âmbito legítimo da educação das subjetividades, pois a formação da identidade perpassa diversos dispositivos e personalidades culturais. As representações culturais envolvidas nas imagens pictóricas estão apenas relacionadas a uma personalidade reconhecida conscientemente dentro da cultura e com as marcas do lugar dessa identidade na cultura. Dessa forma, as subjetividades são atravessadas por modelos identitários 
difundidos pelas imagens estampadas em filmes, brinquedos, roupas, revistas, etc.

Os filmes da Disney têm a pretensão de ensinar o que é considerado correto, ensinar um comportamento e uma postura ideal. Em seu artigo Os filmes da Disney são bons para os seus filhos?, Giroux (2004) problematiza o conteúdo de alguns filmes de animação, questionando as representações de raça e gênero veiculadas nesses produtos, que colaboram para manter uma visão dominante e tradicional das diferenças étnicas, de classe e de gênero. Esses filmes estão imersos em uma "pedagogia cultural" e estão revestidos de autoridade e legitimidade para ensinar às crianças o que é justo e correto. Para Giroux (1995a, p. 52), essas produções "anulam questões complexas, diferenças culturais e lutas sociais”. Assim, a Disney transforma os espaços tradicionais de educação da infância, ampliando o poder da cultura por meio de práticas significantes, que utilizam a imagem para ensinar, fazendo uso dos prazeres da imagem em detrimento da análise crítica e exigências intelectuais (GIROUX, 1995a, 1995b, 2004). As animações produzidas pela Disney se especializaram em divulgar alguns valores culturais, como o amor romântico, a juventude, a heterossexualidade, a pele branca e a cultura ocidental (WOHLWEND, 2008).

Autores como Gomes (2000), Giroux (2004), Hurley (2005), Lacroix (2004), Malfroid (2009), Rozario (2004), Silverman (2009), Matyas (2010), Wohlwend (2008) classificam e agrupam o conjunto de princesas em dois grupos: o primeiro grupo representado por Branca de Neve, Cinderela e Aurora, que formam um grupo de princesas que são apresentadas como sendo belas, dóceis, bondosas e românticas, ligadas aos afazeres domésticos e à religiosidade, além disso, sonham com o príncipe encantado que as salvará dos perigos para em seguida se casar com elas, formando famílias ricas e felizes para sempre.

Já o segundo grupo de princesas é formado pelas personagens mais recentes, como Ariel, Bela, Pocahontas, Mulan, Tiana e Rapunzel, as quais são retratas nos filmes como sendo menos passivas e que não ficam mais sonhando e esperando a chegada do príncipe em um cavalo branco (GOMES, 2000; GIROUX 2004; HURLEY, 2005; LACROIX, 2004; MALFROID, 2009; ROZARIO, 2004; SILVERMAN, 2009; MATYAS, 2010; WOHLWEND, 2008). Visando facilitar a análise separamos esses dois grupos de princesas, em duas subseções que seguem: as Princesas Clássicas Belas e Românticas e as Princesas Ativas e Corajosas.

\section{Princesas Clássicas, Belas e Românticas}

As primeiras princesas da Disney estavam inscritas em um ideal de comportamento considerado civilizado, nobre, apresentando com um cuidado especial às regras de etiqueta, ao decoro e à higiene. Essa “distinção social” se exprimia por “sentimentos nobres”, e se exteriorizava 
por serem belas, dóceis, polidas, passivas, laboriosas e controladas (CANTON, 1994).

A primeira princesa a ser lançada foi Branca de Neve, no ano de 1949. Gabler (2009) afirma que havia uma disputa entre os desenhistas do estúdio, encarregados de produzir a figura animada de Branca de Neve, que discordavam da imagem que a personagem deveria ter. Um dos desenhistas empregava um aspecto infantil e inocente à princesa, outro, a desenhava mais crescida e ativa. A imagem de uma menina meiga e inocente sobressaiu e, ao longo dos anos, tem sido empregada em outras princesas (GABLER, 2009).

Cinderela foi lançada em 1950 e Walt Disney não acreditava no sucesso do filme, pois não havia sido criado feito com todo cuidado e empenho como o da Branca de Neve. Contudo, com sua marcante trilha sonora, a dramática história da princesa, sua simpática fada madrinha e um enredo secundário com bondosos ratos antropomorfizados, perseguidos por um maldoso felino, fez muito sucesso e recebeu as melhores críticas da época.

Em 1959, foi lançado o filme A Bela Adormecida, protagonizado pela princesa Aurora. Walt Disney envolveu-se principalmente no visual do filme, procurando aprimorar mais o desenho dos personagens e dos cenários. A princesa Aurora foi criada usando como modelo as estrelas de cinema que faziam sucesso na época.

Essas três heroínas românticas apresentam uma branquitude da pele, um andar gracioso, vOz cálida, cabelos sedosos, macios e fartos. A relação entre a aparência das princesas e seu caráter é explicitada pelos contos, associando a brancura da pele de Branca de Neve e os cabelos loiros de Cinderela e a bondade da Aurora. A relação entre bondade e cabelos loiros é bastante antiga, sua luminosidade dourada é comparada com a beleza e o brilho do ouro.

\begin{abstract}
A loirice, uma manifestação em particular dos cabelos, e suas muito observadas associações sexuais com os saudáveis raios de sol, com a luz, e não com a escuridão, evoca o durável e incorruptível ouro; qualquer cabelo prometia crescimento, e os cabelos loiros prometiam riquezas. As riquezas da heroína dos contos de fadas - sua bondade, fertilidade e fartura - estão simbolizadas em seus cabelos (WARNER, 1999, p. 417).
\end{abstract}

Cabelos escuros, crespos, despenteados são tradicionalmente relacionados ao selvagem, ao descuido, ao relaxamento e à maldade. Em contrapartida, cabelos curtos nas mulheres indica liberdade, desapego às formas vigentes de feminilidade, sendo alvo de medo e punição. Segundo Warner (1999), Joana d'Arc morreu, entre outros motivos, pelo seu corte de cabelo masculino, além das acusações de bruxaria. A heresia dos seus modos masculinos de se vestir e de cortar os cabelos foi digna de punições cruéis.

Frida Kahlo (1907-1954), pintora mexicana, também abriu mão de seus longos cabelos quando foi deixada por seu marido, Diego Rivera. Ela cortou seus cabelos, vestiu um dos ternos dele 
e fez um autorretrato, sentada com as pernas abertas e os seus cabelos espalhados pelo chão, formando a figura de uma serpente. Como um ex-voto católico, agradecendo uma graça concedida, escreveu no alto da figura: "Olhe, se eu a amava, era pelo seu cabelo. Agora que está careca, não a amo mais" (Warner, 1999). Cabelos longos indicam feminilidade ao estilo das princesas. Cortá-los denota uma "libertação" desse padrão e se torna passível de crítica e estranhamento.

\begin{abstract}
Se nos esquecermos de que os contos de fadas interagem com circunstâncias sociais, deixaremos de entender como a princesa loira exemplar se tornou um instrumento severo para controlar mocinhas [...] As convenções dos contos de fada, a beleza radiante e bondade da heroína tornaram-se clichês usados por moralistas para impor disciplina (e aparência) às meninas em idade de crescimento. $\bigcirc$ bom comportamento trazia recompensas; beleza, apelo sexual, a própria desejabilidade que as heroínas costumavam apresentar como sendo tão dolorosa e problemática. (WARNER, 1999, p. 42I).
\end{abstract}

Além de modelo de beleza, as princesas também eram apresentadas como virtuosas, bondosas, de reto caráter, de candura e idealizadas tal qual a Virgem Maria (CUNHA, 1999). Elas apresentavam bom comportamento e passividade inclusive não agiam para transformar os seus destinos e as suas vidas cabendo essa tarefa aos animais, as fadas madrinhas e outros personagens.

Nesses contos, as regras sociais da aristocracia são referendadas, como a etiqueta da corte, os cuidados com o ambiente de convívio, o requinte da culinária, a educação, a higiene do corpo. No século XVII as regras de etiqueta eram vistas como uma pequena ética, qualquer desvio era considerado falta de escrúpulo e poderia gerar intrigas ou até arruinar posições políticas (GOMES, 2000). A etiqueta barroca instituiu regras disciplinares para rebuscar o corpo, ostentando poder através das vestimentas elaboradas, muitas joias, maquiagem, sapatos de salto alto, perucas ornamentadas, bem como os gestos, as danças e os maneirismos. É o controle sobre o corpo, a postura e o comportamento requintado que define o status social dos sujeitos através de uma especularização dos corpos. Com a propagação da higiene, esta se torna um dos parâmetros para considerar alguém como "culto" e "correto". A limpeza dos corpos e o saneamento dos espaços tornaram-se fundamentais para a "prática do bem" (GOMES, 2000).

Branca de Neve aparece lavando a escadaria externa do palácio logo no início do filme, mais tarde, ela chega à casa dos anões e faz uma "faxina geral" em uma das cenas mais longas em que a princesa, com meiguice e bom humor, se surpreende com a bagunça e a sujeira e distribui tarefas para os animais da floresta que a acompanham. Ela também prepara sopa para os anões e os ensina o modo correto de tomá-la e, além disso, exige que os anões se lavem antes da refeição. Em Cinderela, há um destaque para os cuidados matinais com o corpo e depois com as tarefas domésticas como alimentar os animais, preparar as refeições, servir a madrasta e suas filhas e limpar a casa. Já no filme 
da A Bela Adormecida, as cenas de higienização não têm grande destaque, apesar de a princesa Aurora aparecer varrendo e limpando as aberturas de uma janela. Assim, essa princesa indica o início do processo de mudança das representações das princesas em que Aurora mostra interesse por amigos e rapazes e não apenas por tarefas domésticas e de limpeza. Aurora inaugura um sentimento de ser incompreendida pelas tias fadas, fazendo surgir um discurso de incompatibilidade de gerações, o qual foi mais bem retratado nas princesas mais atuais.

As princesas são imagens do "bem supremo", representado por condutas virtuosas e comportamentos eleitos como os corretos. A bondade é expressa por meio da sua aparência que pode ser observada por sua exibição, que garantiu o final feliz de suas histórias. Assim, essas princesas "ensinam" que o modelo de beleza que apresentam expressa bondade e garante a "verdadeira felicidade".

A preocupação com as vestimentas também é um tema recorrente nos filmes dessas princesas. Branca de Neve aparece com roupas remendadas no início do filme e se esconde atrás da cortina ao se encontrar com o príncipe, demonstrando vergonha por suas vestes simples. Cinderela aparece folheando um catálogo de moda, procurando um modelo para reformar um vestido para ir ao baile. A confecção do vestido de Aurora, no dia do seu aniversário, é um elemento importante do filme, pela discussão em torno da definição se seria azul o rosa pelas fadas. Embora culturalmente a cor rosa seja atribuída às meninas, a cor azul está bastante presente nos filmes e nos produtos das princesas, por ser uma das cores tradicionalmente nobres. $\mathrm{O}$ azul simboliza o que é tido como celestial, superior, elevado. É a cor do manto da Virgem Maria, da fada de Pinóquio, da fada madrinha de Cinderela, da fada Primavera. O azul sugere paz, tranquilidade, calma. Além disso, a bondade das princesas é reafirmada por seu padrão de beleza magro, de abdômen reto, pele branca, nariz pequeno, cabelos sedosos, além de seu cuidado com a higiene do corpo, seus gostos por vestimentas refinadas e cores nobres.

Ainda hoje, a nobreza continua sendo um espaço social idealizado que distingue a vida das pessoas pertencentes às classes mais abastadas em relação às classes menos favorecidas assim como nos séculos passados. As famílias reais da Europa e do Oriente têm um importante espaço reservado na mídia e suas vidas estampam manchetes e noticiários que informam sobre o cotidiano daqueles que possuem o "sangue azul”. Seu cotidiano é retratado em casas luxuosas, com ares aristocráticos, decorados com objetos alusivos aos palácios neoclássicos e ao luxo da burguesia pós-industrial.

$\mathrm{Na}$ educação da menina contemporânea, há uma incitação a "se comportar como uma princesa", reafirmado no glamour dos bailes de debutantes e nas festas de casamento. É costume usar, nesses eventos, vestidos ao estilo daqueles usados pela aristocracia dos séculos XVIII e XIX, caracterizado por suas saias longas e bordados com pedrarias. Vestir-se como uma princesa é a 
realização de um "sonho" para muitas meninas e mulheres ansiosas por travestir-se com características semidivinas. O conto da Cinderela lembra também o sonho das meninas de tornaremse modelos e serem famosas ao desfilarem nas passarelas ou serem fotografadas para grandes grifes internacionais. A gaúcha Gisele Bündchen é um exemplo entre tantas personificações desse conto: uma simples menina nascida no interior do Rio Grande do Sul, que se tornou uma top-model internacional, destacando-se nas mais nobres passarelas da Europa.

Ao mesmo tempo em que a mídia constrói um glamour sobre a carreira de modelos, ela alerta, com menos veemência, sobre a "difícil" vida dessas jovens e dos perigos das dietas em excesso. O que não impede que as meninas aspirantes a essa carreira empreendam inúmeros sacrifícios para serem "descobertas" como a mais nova top. Diversos concursos de beleza e programas do tipo reality show são promovidos com a promessa de selecionar novas modelos e iniciar essa carreira. Uma profissão que se inicia cada vez mais cedo e preocupa provocar uma erotização das meninas, tornando a juventude um modelo de vida e o corpo ainda púbere como o ideal. Em seu texto Afinal, Quem é Mesmo Pedófilo?, Jane Felipe (2006) argumenta que cada vez mais se apresentam na mídia imagens de meninas em poses sensuais, erotizando o corpo infantil. Como essas imagens estão cada vez mais disseminadas pelos meios de comunicação, tornaram-se praticamente "naturais" em nosso cotidiano. Dois exemplos de meninas que estampam imagens muito erotizadas em anúncios em revistas para adultos são Thylane Lena-Rose Blandeau e Kaia Gerber, ambas com dez anos. Thylane tem aparecido nas capas da revista Vogue Paris com maquiagem, roupas e cabelos ao estilo das modelos adultas e em poses provocantes. O ideal de beleza feminina vem sendo alterado de corpos extremamente magros para corpos de meninas púberes, o qual se constitui em um ideal praticamente impossível para mulheres adultas.

Como afirma Bauman (2008), em Vida para Consumo, o consumismo contemporâneo não se trata de satisfazer necessidades ou o desejo de possuir bens, mas de desejar o desejo de possuir sempre mais. O desejo proferido nesses anúncios com meninas em poses erotizadas é aquele que não pode ser cumprido, pois usar as imagens de meninas na puberdade para vender produtos destinados às mulheres adultas é despertar um desejo que não poderá ser saciado, alimentando uma procura incessante por moda e beleza em uma tentativa infrutífera de parecer uma menina de dez anos. $\mathrm{O}$ culto do corpo púbere como ideal feminino está cada vez mais em voga, propagando um ideal de corpo inatingível.

Raros filmes clássicos da Disney são protagonizados por personagens que não sejam possuidores dos padrões hegemônicos de beleza, somente nos filmes Dumbo e O Corcunda de Notre-Dame e no curta-metragem O Patinho Feio é que personagens considerados diferentes são os protagonistas. Todavia, também essas narrativas seguem a estrutura tradicional da história de 
personagens defeituosos, ou seja: sofrem dificuldades e preconceitos, são cruelmente discriminados, mas através de um dom especial, ou por sua "beleza interna", o personagem compensa sua deformidade. Dumbo é rechaçado por suas orelhas grandes até descobrir que pode voar; Patinho Feio sofre discriminação e é abandonado até ser descoberto como um cisne; Quasímodo, de o Corcunda de Notre-Dame, é excluído até provar sua bondade interior, mas mesmo assim, não é digno de viver o amor romântico.

Já no filme da de Branca de Neve são os anões que representam o "diferente" com inocência e características infantis apresentam uma ingenuidade e bondade, expressas principalmente pelo personagem Dunga, ajudando a princesa em seu drama. Essa infantilização dos anões da versão dos Irmãos Grimm representa a intenção da Disney de atribuir um toque de comédia e brincadeira aos personagens considerados diferentes.

Por meio do discurso da "beleza interna" Disney atenua o preconceito aos corpos diferentes dos padrões de beleza. Para a Disney, o mal é representado pela feiura, enquanto os heróis demonstram formosura e beleza. Segundo esses preceitos, os sujeitos que apresentam corpos disformes, fora dos padrões estabelecidos, devem compensar esse desajuste com certa candura, ingenuidade, bondade e "beleza interna" para serem diferenciados dos vilões. Luz e trevas são representadas como a antítese entre bem e mal, própria dos preceitos medievais. Os cabelos claros, abundantes e longos, como os da Cinderela e da Aurora, a pele extremamente clara de Branca de Neve simbolizam a clareza da luz celestial, da luz solar, do diurno e das cores claras que se opõem à escuridão tidas como representação do mal e do primitivo.

Vemos muitos desses preceitos dos contos clássicos virarem piadas nas telas do cinema nos filmes do Schrek produzidos pela Dremworks em que o ogro representa todas as características opostas à cultura hegemônica da elite aristocrática europeia: é gordo, de cor diferente, mal vestido, tem nariz grande e achatado, nenhuma etiqueta e higiene. Schrek vive em um pântano sujo, malcheiroso, sua alimentação não é refinada, ou seja, é um "verdadeiro ogro". No primeiro filme, todos os seres de contos de fadas são banidos do reino de Lorde Farquaard por serem diferentes e “sujarem seu mundinho perfeito". Ao banir esses personagens, há uma representação da exclusão de todos aqueles que são considerados anormais. Schrek parte então para uma empreitada para reaver o seu pântano e precisa salvar a princesa Fiona das garras de um poderoso dragão.

Ao longo das tramas, encontra diversos personagens que também são discriminados, como o burro falante, o gato de botas e tantos outros que não são o que aparentam: Fiona é uma princesa com modos de ogra, o dragão é uma fêmea que se apaixona pelo burro, Lorde Farquaard é baixinho e covarde, o rei é um sapo, a fada madrinha é má e o príncipe é vaidoso e egoísta.

Em diversos aspectos do filme, fica evidente que os modos de viver de Schrek e seus 
companheiros são próprios das classes mais pobres, sem requinte e poder. O reino Tão Tão Distante, que une elementos das cortes europeias com Hollywood, Califórnia, nos Estados Unidos da América, está muito afastado da cultura popular dos simples moradores do pântano. Branca de Neve, Cinderela, Bela Adormecida e Rapunzel moram em mansões na glamorosa e encantada Tão Tão Distante. Fiona, princesa de dia e ogra à noite, graças a um feitiço, escolhe um amor não convencional com o ogro, negando Lorde Farquaard e o Príncipe Encantado.

Ao conhecer Tão Tão Distante e o Príncipe Encantado, Schrek se sente deslocado e vai atrás de uma poção que garanta seu "final feliz". Fada Madrinha, ao flagrar Schrek roubando uma de suas poções, abre diversos livros de contos de fadas mostrando que em nenhum deles o ogro tem um final feliz, com isso reafirma que poucos são os escolhidos para viver o "verdadeiro amor".

A poção mágica que garante o final feliz transforma Schrek em um homem com características próprias da masculinidade hegemônica: branco, alto, forte e "musculoso", enquanto Fiona poderia se tornar humana novamente. Assim, "abriu-se um momento para a possibilidade de fazerem-se belos e aceitos por todos" (CORSO, CORSO, 2011, P. 172). Mesmo sendo um filme que se propõe a desconstruir muitos dos estereótipos dos filmes da Disney, as suas narrativas guardam muito das clássicas histórias do sujeito discriminado por suas diferenças, que revela uma "beleza interna" íntegra e valorosa, merecendo também ter o seu "final feliz".

Princesas Ativas e Corajosas, Mas Nem Tanto!

As princesas dos filmes mais recentes, Ariel, Bela, Pocahontas, Mulan, Tiana e Rapunzel, são menos passivas e não ficam mais sonhando e esperando a chegada do príncipe em um cavalo branco (GOMES, 2000). Mais ativas, elas lutam e vão atrás dos homens de seus sonhos, salvam suas vidas, ensinam-os a comer decentemente, a respeitar o equilíbrio da natureza e a honestidade. A Pequena Sereia canta "quero mais" e enfrenta seu pai e as leis do fundo do mar para casar com o príncipe. Bela, de braços abertos em uma cena do filme, canta o desejo de uma vida maior que a da sua aldeia. Jasmine deseja casar por amor e o defende, soltando passarinhos de dentro de uma gaiola. Mulan, Tiana e Rapunzel também apresentam um dinamismo, tomam atitudes radicais, resistem aos seus opressores, fazendo com que seus pares masculinos pareçam acomodados (GOMES, 2000).

A primeira vista, o filme A Pequena Sereia pode parecer um filme feminista, pois Ariel entra em conflito com seus pais e deseja explorar o mundo dos humanos. 
Mas no final, o conflito para obter sua independência do pai, Triton, e o senso do esforço desesperado que a motiva se dissolvem quando Ariel faz um pacto mafistoléfico com Úrsula: a sereia negocia sua voz para ganhar um par de pernas, conquistando assim o belo príncipe Eric. (GIROUX, 2004, p. 97).

O filme pretende ensinar que abandonar o poder possibilita a conquista do tão esperado final feliz, desposando um belo príncipe. Uma das mensagens significativas do filme é dada pela maquiavélica Úrsula, vilã da trama, ao afirmar que não há problema em Ariel abrir mão da sua voz, pois os homens preferem mulheres que não falam. A mensagem é reafirmada quando o príncipe beija Ariel, mesmo sem "terem trocado uma palavra". Ao renunciar aos seus poderes ela é premiada com a possibilidade de viver o amor romântico (GIROUX, 2004).

O mutismo de Ariel representa o silêncio feminino desejado pela cultura dominante, mais um dos aspectos que fazem parte de outros ideais impostos às mulheres pelas redes de poder. Talvez este seja um dos motivos para as mães morrerem nos contos de fadas, pois a representação da "mulher perfeita" implica na autoanulação e no silêncio, a ponto de desaparecerem nas narrativas.

No filme Aladim, a princesa Jasmine é coadjuvante da história, apenas um objeto de desejo do protagonista, um jovem ladrão das ruas. São os homens da trama que definem a vida de Jasmine, mesmo que ela batalhe para não realizar um casamento arranjado por seu pai para desposar Aladim, é ele que assegura sua felicidade casando-se com ela no final do filme. Aladim tem um visual árabe bastante atenuado, seu nariz é fino, o tom de pele bem mais claro do que os personagens malvados, que são apresentados com a pele mais escura, nariz maior e barbas (GIROUX, 2004).

A complexidade das relações entre homens e mulheres torna-se um pouco mais evidente no filme A Bela e a Fera. Bela é um pouco mais independente do que as princesas anteriores, pois está sempre lendo e renega o personagem Gaston, o "bonitão" do vilarejo onde vive. Bela se apaixona pela Fera que a mantém prisioneira na tentativa de conquistá-la. Bela ensina bons modos, etiqueta, controle das emoções e dança para a Fera. Ela o transforma no novo modelo de masculinidade do homem sensível, atencioso e amoroso (GIROUX, 2004). O filme apresenta uma mudança nos comportamentos esperados dos homens ao apresentar a protagonista renegando Gaston, com sua masculinidade tirana e narcisista, para casar-se com a Fera, transformando-o em um homem menos sexista.

O discurso multiculturalista que cresceu na década de 90 pelas demandas globalizantes fez com que os estúdios da Disney criassem heroínas de diferentes etnias, fomentando a venda dos seus produtos. Nessa época, foram criadas Pocahontas, que representa uma americana nativa, e Jasmine, uma princesa árabe que tem suas características étnicas atenuadas para não se distanciar do padrão de beleza hegemônico (GOMES, 2000; GIROUX, 2004; HURLEY, 2005; LACROIX, 2004; 
MALFROID, 2009; ROZARIO, 2004; SILVERMAN, 2009; WOHLWEND, 2008). Somente em 2009 é que foi apresentada a primeira princesa negra.

A princesa Tiana, do filme A Princesa e o Sapo é a primeira representação da Disney na franquia Disney Princess de uma mulher afro-americana. Tiana segue a mesma linha das princesas contemporâneas: é determinada, independente e forte. O trabalho duro como a melhor maneira de alcançar seus objetivos é seu lema.

A princípio, parece ser um filme que retrata de forma positiva homens e mulheres afro-americanos; contudo, as representações de gênero, etnia e classe social ainda seguem os mesmos valores que os filmes anteriores. Mesmo Tiana sendo uma profissional de sucesso, independente e determinada, isto não é suficiente para a sua realização; o amor romântico e a união com a figura masculina ainda são exaltados nessa produção, como se a felicidade somente fosse possível a partir do casamento ideal. Quanto às questões de etnia e classe social, a comunidade negra é representada conformada com a hegemonia da etnia branca, que ocupa cargos e funções de poder no filme. Essa conformidade com os valores burgueses e com a supremacia da etnia branca produz efeitos nas identidades infantis, formando modos de pensar e agir. Por meio de suas produções a Disney é construtora mundial de representações culturais de gênero, etnia e classe, a partir de um ponto de vista etnocêntrico, privilegiando o patriarcado e a branquitude da pele (GOMES, 2000; GIROUX 2004; HURLEY, 2005; LACROIX, 2004; MALFROID, 2009; ROZARIO, 2004; SILVERMAN, 2009; MATYAS, 2010; WOHLWEND, 2008).

Em Pocahontas, o tema do racismo é apresentado mesmo que de forma sutil, pois essa animação foi projetada para apresentar uma história real da colonização americana, cujos conflitos, exploração e sofrimento são ignorados e propositalmente apagados da narrativa. Pocahontas é uma nativa americana, retratada com um visual ao estilo da Barbie, que se apaixona por John Smith. Disney transforma o impiedoso genocida de índios em um herói virtuoso e espiritualizado. Mesmo sendo retratada como uma mulher forte e decidida, Pocahontas é um retrato machista e racista dos nativos americanos (GIROUX, 2004).

Uma das políticas da Disney é vender a inocência em um jogo de poder cultural que lhes permite reescrever a história, influenciando a compreensão sobre o passado. Através desta inocência, a história pode ser reescrita, ocultando seu lado mais perverso, com certo apelo à nostalgia. O passado é visto como potencial pedagógico e ideológico, que pode assegurar seus interesses de mercado e poder. A inocência é um discurso de dominação, um dispositivo pedagógico para educar as pessoas a verem, nas narrativas históricas, representações e práticas culturais que passam a ser veiculadas/apresentadas pela Disney.

A pedagogia cultural da Disney produz identificações, através de seus produtos, que definem a 
história dos Estados Unidos por meio de certos discursos, como a narração de sua história como em um conto de fadas, excluindo os elementos subversivos. Por meio das suas representações de inocência feliz, encobre valores conservadores, colonialistas, defendendo a supremacia da classe média branca e heterossexual, produzindo e reafirmando discriminações raciais e de classe por meio de suas narrativas e defesa dos "valores de família".

Em seu mais recente filme, Enrolados, protagonizado pela princesa Rapunzel, Disney lança sua própria versão da história. Assim como Branca de Neve, Rapunzel é retratada como uma menina inocente, seus longos e brilhantes cabelos loiros contrastam com a negritude dos cabelos de sua madrasta má. Novamente, a Disney perpetua a ideia de que o claro e brilhante está ligado ao bom, enquanto o escuro e negro é associado ao mau.

Rapunzel é uma princesa ativa, seu lema é lutar pela realização dos seus sonhos e sua principal virtude é transformar vilões em mocinhos, inclusive seu par romântico, um ladrão que se torna príncipe pelo inevitável casamento final. Esse padrão de valores e de características físicas e comportamentais são as formas contemporâneas de educar e governar as subjetividades das crianças. Educar não é mais um ato restrito à família e à escola, mas aos meios de comunicação também, que fazem uso da mais recente tecnologia e dos recursos mais avançados para construir um imaginário de fantasia e sonho. Por meio dessa sedução visual, Disney governa a educação de crianças e jovens, fomentando seus valores (GOMES, 2000; GIROUX, 2004; HURLEY, 2005; LACROIX, 2004; MALFROID, 2009; ROZARIO, 2004; SILVERMAN, 2009; MATYAS, 2010; WOHLWEND, 2008).

Não se pode deixar de citar que tanto nos filmes das princesas clássicas como nos filmes das princesas mais atuais, o amor romântico heterossexual prevalece, garantindo a "verdadeira felicidade" das heroínas. Esse amor é reservado aos "bons de coração", àqueles que se sacrificam pelo próximo. As bruxas, os vilões e os malfeitores são solitários. Segundo Gomes (2000), os vilões são os "malamados" das histórias, mostram-se melancólicos, ranzinzas e procuram compensar suas amarguras buscando o poder.

\footnotetext{
Quando não realizamos o ideal imaginário de amor, buscamos explicar a impossibilidade culpando a nós mesmos, aos outros ou ao mundo, mas nunca contestando as regras comportamentais, sentimentais ou cognitivas que interiorizamos quando aprendemos a amar (COSTA, 1998, p. 34-35).
}

O amor romântico é reservado àqueles que possuem "virtudes nobres", seguem os padrões de beleza vigentes, os comportamentos certos como coragem, bondade, etc. Há preceitos que estabelecem os modos de amar e também “os estereótipos de quem pode amar quem” (GOMES, 2000, p.170). Assim, o enamoramento romântico raramente contraria preconceitos e diferenças de classe, raça, religião, limitando o grupo de pessoas que "merecem ser amadas" (COSTA, 1998). Há normas para designar quem pode viver o amor e, no caso das princesas, suas características apresentam um 
estereótipo feminino apto para viver o amor romântico.

O amor romântico foi um sentimento construído historicamente e incorporado aos valores culturais e é fortemente disseminado pela Walt Disney. É possível pensar o amor fora dos padrões dos filmes das princesas?

A partir da estética da existência de Foucault (2004), pode afastar-se das concepções romanceadas do amor e vê-lo como uma questão ética. Fora dos controles minuciosos da etiqueta aristocrática, Foucault (2004) propõe uma visão do amor como uma experiência afetiva, como uma estática da existência, uma arte sobre si, em que o sujeito, ao se relacionar afetivamente com o outro, se reconstrói moralmente. Nesse conceito de amor, não há preceitos, normas, roteiros a serem seguidos, mas "procedimentos pelos quais se exerce seu controle sobre si próprio e da maneira pela qual se pode estabelecer a plena soberania de si" (FOUCAULT, 1998, p. 234). Essa ética do companheirismo, da amizade e do amor rompe com o imperialismo do amor romântico.

A partir das figuras das princesas, apresentadas pela Disney é possível traçar um panorama da feminilidade contemporânea, pois além de serem ícones de consumo, são tratadas como modelos femininos que devem ser apresentados às crianças desde tenra idade, representando o arquétipo das heroínas dos contos de fadas e apresentando um modelo de "feminilidade ideal" (WOHLWEND, 2008).

Era uma vez

Somente com a problematização e a reflexão sobre essas imagens é possível ajudar as crianças a desenvolverem um senso crítico sobre os preconceitos de corpo, raça, etnia, geração e comportamento. Encontra-se aí a importância da educação para que se possa pensar modos de produzir uma maior conscientização ética. 
Referências

BAUMAN, Zygmunt. Vida para Consumo. São Paulo: Zahar, 2008.

CANTON, Kátia. E o Príncipe Dançou... O conto de fadas, da tradição oral à dança contemporânea. São Paulo: Ática,1994.

CORSO, Diana. CORSO, Mário. A Psicanálise na Terra do Nunca. Porto Alegre: Artmed, 2011.

COSTA, Jurandir Freire. Sem Fraude nem Favor, estudos sobre o amor romântico. Rio de Janeiro: Rocco, 1998.

CUNHA, Susana R. Vieira da. As Transformações da Imagem na Literatura Infantil. In: Pillar, Analice Dutra (org.) A Educação do Olhar. Porto Alegre: Mediação, 1999.

DELEUZE, Gilles. Foucault. São Paulo: Brasiliense, 1998.

DISNEY CONSUMER PRODUCTS. Toys. 2007. Disponível em:

http://licensing.disney.com/Home/display.jsp?contentId=dcp_home_ourbusinesses_toys\&forPr int $=$ false\&language $=$ en\&preview $=$ false\&region $=0$. Acesso em: 10 de out. de 2011.

FELIPE, Jane. Afinal, quem é mesmo pedófilo? Cadernos Pagu, n. 26. Campinas, 2006. P. 201 223.

FOUCAULT, Michel. A Hermenêutica do Sujeito: curso dado no Collège de France (19811982). São Paulo: Martins Fontes 2004.

Graal,1998b.

O cuidado de si. In: FOUCAULT, M. História da sexualidade. V. 3: Rio de Janeiro,

GABLER, Neil. Walt Disney: o triunfo da imaginação americana. Tradução Ana Maria Mandim. Osasco: Novo Século, 2009.

GIROUX, Henri. A Disneyzação da Cultura Infantil. In: Silva, Tomaz Tadeu; Moreira, Antônio Flávio. Territórios contestados. Campinas: Mercado das Letras, 1995a.

Memória e Pedagogia no Maravilhoso Mundo Disney. In: Silva, Tomás Tadeu da. Alienígenas em sala de aula. Petrópolis, Vozes, 1995b.

Os filmes da Disney são bons para seus filhos? In: STEINBERG, Shirley R.

KINCHELOE, Joe L. Cultura Infantil: a construção corporativa da infância. Rio de Janeiro: Civilização Brasileira, 2004.

HURLEY, D. L. Seeing White: Children of Color and the Disney Fairy Tale Princess. The Journal of Negro Education; Summer 2005; 74, 3; Research Library

p. 221.

LACROIX, Celeste. Images of Animated Others: The Orientalization of Disney's Cartoon Heroines From The Little Mermaid to The Hunchback of Notre Dame. DepartmenI of Communication. College of Charleston. Geori-e Street. Charleston, 2004.

LARROSA, Jorge. Tecnologias do eu e educação. In: Silva, T. T. da (org.). O sujeito da educação: estudos foucaultianos. Petrópolis: Vozes, 1996.

MALFROID, Kirstein. Gender, Class, and Ethnicity in the Disney Princesses Series. Universiteit Gent Faculteit Letteren en Wijsbegeerte, 2009.

MATYAS, Vanessa. Tale As Old As Time: A Textual Analysis of Race and Gender in Disney 
Princess Films. Graduate Major Research Papers and Multimedia Projects, 2010.

ROZARIO, Rebecca-Anne. C. The Princess and the Magic Kingdom: Beyond Nostalgia, the Function of the Dis...Women's Studies in Communication, 2004; 27, 1; Research Library pg. 34.

SILVA, Tomaz Tadeu. Documentos de Identidade: uma introdução às teorias do currículo. Belo Horizonte: Autêntica, 2007.

SILVERMAN, Rachel Anne. New Dreams, Old Endings: Searching for "A Whole New World" in Disney Second-Wave Animated Romance Films. Faculty of Wesleyan University. Departmental Honors in Sociology, 2009.

WARNER, Marina. Da Fera à Loira: sobre contos de fadas e seus narradores. São Paulo: Companhia das Letras, 1999.

WOHLWEND, Karen E. Damsels in Discourse: Girls Consuming and Producing Identity Texts Through Disney Princess Play Reading. Research Quarterly 44(1) p. 57-83, 2008. 